\title{
Model Dan Strategi Pendidikan Nilai Pada Pendidikan Dasar, Menengah Dan Pendidikan Tinggi
}

\author{
Aris Saputro ${ }^{1}$ \\ ${ }^{1}$ Fakultas Ilmu Sosial, Universitas Negeri Malang \\ Email: arissaputro476@gmail.com
}

\begin{abstract}
Abstrak
Tujuan dari penulisan artikel ini adalah memahami model dan strategi pendidikan nilai pada pendidikan dasar, menengah dan pendidikan tinggi. Pendidikan merupakan satu hal mendasar yang dibutuhkan oleh setiap manusia. Hasil pembahasan model dan strategi pendidikan nilai yaitu Pendidikan nilai merupakan upaya pembentukan sikap pribadi anak didik yang menjadikan semakin berakhlak dengan sistem model teknik pengungkapan nilai, model pengembangan kognitif moral, model analisis nilai, dan model tindakan sosial serta beberapa strategi yang membentuk pribadi individu menjadi bersahaja. Kesimpulan bahwasanya dengan adanya model dan strategi pendidikan nilai pada pendidikan dasar, menengah dan pendidikan tinggi mampu mengembangkan nilai-nilai yang humanis.
\end{abstract}

Kata kunci: Model, Strategi, Pendidikan Nilai

\begin{abstract}
The purpose of writing this article is to understand the model and strategy of value education in primary, secondary, and higher education. Education is one of the fundamental things every human being needs. The result of the discussion of value education models and strategies is that value education is an effort to establish the personal attitudes of students that makes increasingly sincere with the system of value disclosure techniques, moral cognitive development models, value analysis models, and social action models as well as some strategies that make individual personality understated. The conclusion that with the model and strategy of value education in primary, secondary and higher education can develop humanist values.
\end{abstract}

Keywords: Model, Strategy, Grade Education

\section{PENDAHULUAN}

Pendidikan nilai memiliki peranan penting dalam upaya mewujudkan manusia Indonesia yang unggul. Pembinaan terkait nilai dalam pendidikan merupakan sarana untuk menangkal pengaruh-pengaruh negatif baik berasal dari dalam dan luar negeri. Pembinaan mengenai nilai adalah kebutuhan mendasar karena salah satu cara mendukung tujuan dari pendidikan nasional secara utuh. Pasal 3 Undang-Undang Republik Indonesia Nomor 20 Tahun 2003 tentang Sistem Pendidikan Nasional (UU Sisdiknas), menyatakan: "Pendidikan nasional berfungsi mengembangkan kemampuan dan membentuk watak serta peradaban bangsa yang bermartabat dalam rangka mencerdaskan kehidupan bangsa, bertujuan untuk berkembangnya potensi peserta didik agar menjadi manusia yang beriman dan bertakwa kepada Tuhan Yang Maha Esa, berakhlak mulia, sehat, berilmu, cakap, kreatif, mandiri, dan menjadi warga negara yang demokratis serta bertanggung jawab."

Berakhlak mulia atau memiliki tata krama merupakan dasar untuk membentuk masyarakat yang beradab (civil society). Pada Era Reformasi sekarang, kebebasan bertindak banyak yang melampaui batas dan dapat berpotensi atau membuka kran perilaku negatif, diantaranya: tawuran pelajar, perang antarsuku, penghujatan di media sosial, perusakan tempat ibadah, lembaga kantorkantor pemerintahan dan lainnya. Bangsa Indonesia saat ini sedang mengalami penurunan nilai akhlak yang seharusnya tidak 
WAHANA

Volume 72, Nomor 2, Desember 2020

terjadi jika nilai-nilai dihayati dan dijunjung tinggi. Kemerosotan nilai moral dikarenakan kurang penanaman akhlak atau budi pekerti yang tepat dalam masyarakat, sekolah bahkan terpenting pada lingkungan keluarga.

Ketidakefektifan model dan strategi pendidikan nilai menimbulkan kurang dijiwainya makna pendidikan seutuhnya. Tidak sedikit pengajaran nilai berhenti dalam tataran teori dan dalam implementasi kurang. Implementasi nilai-nilai moral pada peserta didik pada pendidikan dasar, menengah dan perguruan tinggi dapat dicapai apabila adanya langkah yang mudah dipahami atau sederhana. Saat mengimplementasikan nilai-nilai moral tersebut perlu adanya keseimbangan dan keselarasan pada tataran nilai estetika dan nilai kebenaran (logika). Kebenaran akan adanya nilai dapat membentuk pola sebuah pendidikan dan menjadikan proses edukasi yang mencerahkan. Maka, disinilah perlu adanya konsep dalam pendidikan yang bertujuan mewujudkan insan yang bernilai religius.

\section{METODE PENELITIAN}

Jenis Penelitian ini menggunakan deskripstif kualitatif. Dengan menggunakan sumber bahan primer dan sekunder yang berisi pengetahuan ilmiah baru untuk memahami dan memecahkan permasalahan secara faktual. Bahan/sumber primer meliputi: (a) buku, (b) prosiding seminar, lokakarya, simposium dan sebagainya, (c) laporan studi, (d) laporan teknis, (e) majalah, (f) disertasi dan tesis, dan (g) paten. (2) bahan/sumber sekunder yang menjadi bahan perpustakaan yang berisi informasi tentang bahan primer. Bahan/sumber sekunder ini meliputi sebagai berikut: (a) abstrak, (b) indeks, (c) bibliografi, (d) penerbitan pemerintah, dan (e) bahan referensi lainnya.

\section{HASIL DAN PEMBAHASAN}

3.1. Tinjauan Model dan Strategi Pendidikan Nilai

Secara umum strategi mempunyai pengertian, menurut Syaiful Bahri (2013:5) menjelaskan bahwa strategi merupakan suatu garis-garis besar haluan untuk bertindak dalam usaha mencapai sasaran yang telah ditentukan. Selanjutnya mengenai penanaman pendidikan nilai menurut Khaeran, dapat dilakukan dengan: a. "Model pewarisan yaitu dengan menggunakan cara pemaksaan, indoktrinasi mekanistik, latihan, dan pengulangan.

b. Model pengembangan kesadaran nilai yaitu anak akan menemukan nilai ketika mereka telah mengalaminya sendiri.

c. Model pengembangan nilai etika swasta adalah ketika anak didik tumbuh dan berkembang melalui tahapan perkembangan secara kualitatif yang berbeda antar satu dengan lain (Khaeran, 1993:128)."

Strategi pendekatan pendidikan nilai terdapat beberapa pendekatan dan model. Menurut Djahiri dalam (Qiqi, 2014:71), terdapat 8 (delapan) strategi pada budi pekerti atau pendidikan nilai, sebagai berikut:

a. "Evocation: strategi untuk peserta didik diberikan keleluasaan dan kesempatan dapat bebas mengekspresikan respon afektifnya terhadap stimulus yang diterimanya.

b. Inculcation: strategi terhadap siswa menerima stimulus untuk diarahkan menuju kondisi siap.

c. Moral Reasoning: strategi supaya terjadi transaksi intelektual taksonomi yang tinggi dalam mencari permasalahan.

d. Value Clarification: strategi melalui stimulus terarah supaya siswa ikut mencari kejelasan isi pesan keharusan nilai moral.

e. Value Analysis: strategi supaya siswa berkeinginan melakukan tindakan analisis nilai moral.

f. Moral Awareness: strategi kepada siswa untuk menerima stimulus dan membangkitkan kesadaran terhadap nilai tertentu.

g. Commitment Approach: strategi untuk siswa supaya sejak awal dapat menyepakati adanya pola pikir terhadap proses pendidikan nilai.

h. Union Approach: strategi kepada siswa untuk diarahkan melaksanakan sesuatu yang nyata pada kehidupan."

Maka setelah memahami langkah strategi dari pendekatan pendidikan nilai. Selanjutnya perlunya mengetahui apa saja macam model 
WAHANA

Volume 72, Nomor 2, Desember 2020

pendidikan nilai dan implementasinya di lapisan tingkatan pendidikan. Menurut Hers dalam (Qiqi, 2014:72) menjelaskan empat model pendidikan nilai adalah:

a. "Model pengungkapan nilai adalah suatu teknik yang melihat pendidikan moral sebagai promoting self-awareness and self caring. Model yang bukan mengatasi masalah moral untuk membantu mengungkapkan moral yang dipunyai peserta didik. Pendekatan dilaksanakan melalui membantu peserta didik untuk menemukan dan menilai/menguji nilai yang dimiliki masing-masing agar mencapai perasaan diri. Proses pendidikan ini banyak diterapkan untuk mengimplementasikan pendidikan nilai dan moral dalam tataran mencapai perasaan diri terhadap aspek nilai moral seperti pada tingkatan Pendidikan Anak Usia Dini (PAUD) dan Taman Kanak-Kanak (TK).

b. Model pengembangan kognitif moral: model untuk membantu peserta didik agar berpikir dengan proses pertentangan dengan jelas dan menyeluruh melalui tahapan-tahapan umum serta pertimbangan moral. Pengembangan pendidikan ini bisa diimplementasikan pada tahapan siswa di tingkat Sekolah Dasar/Madrasah Ibtidaiyah (SD/MI) karena pada tahapan ini dapat disesuaikan pula dengan mata pelajaran siswa berbasis tematik seperti mengenalkan siswa pada tahapan-tahapan umum dan pertimbangan moral di masyarakat ataupun lingkungan sekitar siswa. Pada tingkatan siswa di tingkat Sekolah Menengah Pertama/Madrasah Tsanawiyah (SMP/MTs) pun masih relevan.

c. Model analisis nilai: model untuk membantu siswa dalam mempelajari pengambilan keputusan dengan proses langkah demi langkah melalui cara sistematis. Tahapan analisis ini dapat memberikan makna apabila dihadapkan menangani isu kebijakan yang kompleks. Analisis pendidikan nilai ini bisa di terapkan pada siswa pada tingkat Sekolah Menengah Atas, Sekolah Menengah Kejuruan ataupun Madrasah Aliyah (SMA/SMK/MA). d. Model tindakan sosial: model yang mengarah untuk meningkatkan mahasiswa dalam hal pengungkapan, mampu meneliti, dan dapat memecahkan masalah sosial. Untuk model ini dapat diterapkan pada Perguruan Tinggi (PT) jenjang S1, S2 dan S3 karena kajiannya sudah masuk pada ranah tindakan sosial. Ranah tindakan sosial yaitu menggali dan menganalisis tentang nilai itu sendiri dalam kerangka penelitian. Tindakan sosial atau fenomena di masyarakat dilihat dari nilai itu sendiri yaitu dalam aspek kajian penelitian yang mengajarkan arti nilai sesungguhnya kepada mahasiswa untuk kemudian dipahami maksudnya."

Pada konteks mengimplementasikan pendidikan nilai, pendidik perlu memastikan sasaran suatu hal untuk dapat dipahami makna secara keseluruhan. Karena anak didik merupakan subjek yang bukan hanya dibekali untuk memahami nilai dalam tataran teori, namun bagaimana membimbing anak didik untuk mengaktualisasikan nilai luhur pada kehidupan di masyarakat.

Pendidikan diharapkan mampu membuat individu untuk selalu menciptakan kerukunan dalam menjalani kehidupan sesuai dengan nilai luhur di masyarakat. Nilai luhur memiliki esensi makna dan identik dengan pendidikan moral, pendidikan budi pekerti, pendidikan karakter, pendidikan akhlak, dan lainnya yang merupakan satu kesatuan dari pendidikan baik secara formal atau secara informal. Setiap jenjang pendidikan yang ada dalam sistem pendidikan nasional di Indonesia memiliki output untuk membentuk generasi bangsa yang bukan hanya cerdas tapi juga memiliki kepribadian yang luhur.

\subsection{Definisi dan Konsep Pendidikan Nilai}

Pembentukan sikap dan tingkah laku seseorang dimulai dari pendidikan nilai. Smith dan Spranger, memberikan argumentasi bahwa nilai-nilai mewarnai sikap dan tindakan individu karena ia harus senantiasa untuk dimiliki. Max Scheler juga memberikan pengertian, bahwa manusia perlu terus-menerus berusaha mencapai nilai-nilai yang lebih tinggi tingkatannya. Proses internalisasi nilai membutuhkan kemahiran dalam menangkap nilai lewat pengalaman nyata, di antaranya perlu keterbukaan hati-budi, keheningan, ketenangan, dan disposisi batin yang 
WAHANA

Volume 72, Nomor 2, Desember 2020

mendukung; terbuka, percaya, jujur, rendah hati, bertanggung jawab, berniat baik, setia, dan taat (Subur, 2007:4). Sumantri (1993:16) juga memberikan argumentasi, bahwasannya "proses pendidikan bagi orang dewasa dan remaja memerlukan pemahaman pendidikan nilai yang baik di dalam sekolah maupun di luar sekolah. Karena "penentuan nilai" merupakan aktivitas penting yang harus dipikirkan secara mendalam dan cermat. Maka, merupakan tugas dari proses pendidikan agar selalu berupaya meningkatkan nilai moral dalam diri individu dan masyarakat."

Pendidikan "nilai" yang diajarkan oleh seorang pendidik (guru) di kelas merupakan dasar untuk peserta didik dalam berperilaku yang beradab. Implementasi nilai-nilai yang bernilai luhur ketika di sekolah menjadi tugas setiap guru untuk selalu memantau perkembangan. Tingkah laku atau perilaku sesungguhnya yang ditampilkan anak didik tidak hanya sebatas dalam ruang kelas atau dilingkungan sekolah, namun di masyarakat sekitar. Pendidikan nilai dalam lingkungan sekolah dapat dipupuk oleh semua guru, bukan hanya dibebankan kepada guru PKn atau Agama. Karena semua guru memiliki peranan yang sama dalam ikut serta menanamkan pendidikan nilai. Contohnya, seorang peserta didik ketika bermain membuang sampah tidak ke dalam tempatnya, tindakan itu kebetulan terlihat oleh guru matematika, maka guru tersebut berkewajiban menegur peserta didik tersebut agar mengambil sampah itu dan memasukkannya ke tempat sampah.

Pendidikan nilai tidak sekedar pelengkap atau tambahan, tetapi keseluruhan proses peserta didik untuk memperoleh pendidikan yang hakiki. Pendidikan nilai menjadi semakin penting dan mendesak untuk terus dipupuk ditengah arus konsumerisme dan materialisme yang melunturkan nilai-nilai luhur kehidupan. Pengikisan nilai, akhlak, tata krama bukan hanya menyentuh kepada individu yang tinggal di kota metropolitan, namun telah masuk ke desa.

Menanamkan nilai kepada peserta didik perlu mempergunakan model atau strategi alternatif, diantaranya menurut Sita (2018:12) yaitu Pendidikan yang berkualitas tentunya akan mampu menghasilkan sebuah kebudayaan yang berkualitas pula. Begitu dengan kebudayaan yang luhur akan mampu menghasilkan pendidikan yang luhur pula. Apabila pendidikan kurang berkontribusi maka kebudayaan yang dihasilkan juga tentunya akan kurang. Perilaku yang dilakukan terus menerus oleh suatu komunitas di sekolah dalam hal ini bisa peserta didik ataupun semua orang yang ada dalam lingkungan sekolah bisa menjadi sebuah acuan implementasi pendididikan nilai yang baik dan berkualitas bila disertai nilai moral positif sebagai pengejawantahan dari karakter yang telah dibentuk sebagai hasil manfaat implementasi pendidikan nilai yang tentunya telah menjadi pola kebiasaan baru yang dilakukan oleh peserta didik dan semua orang dalam lingkungan sekolah tersebut.

Konsep utama pendidikan nilai adalah menjadikan setiap orang/individu mampu mengimplementasikan nilai-nilai kebaikan dan kebajikan dalam kehidupan secara sadar melalui kemampuan kognitif, emosional dan perilaku. Nilai itu dikelompokkan menjadi tiga kelompok yaitu:

a. Nilai yang berkenaan dengan kebenaran atau yang terkait dengan nilai benar dan salah yang dibahas oleh logika.

b. Nilai yang berkenaan dengan kebaikan atau yang terkait dengan nilai baik dan buruk yang dibahas oleh moral.

c. Nilai yang berkenaan dengan keindahan atau yang jelek yang dibahas oleh estetika.

Kohlberg dalam (Djahiri, 1992:27) memberikan penjelasan terkait pendidikan nilai yang merupakan rekayasa kearah tertentu, diantaranya adalah:

a. "Pengembangan struktur dan pembinaan serta komponen atau potensi pengalaman afektual (affective component and experiences) atau potensi jati diri/hati nurani manusia (the consiense of man) atau suara hati (al-qolb) manusia dengan perangkat tatanan nilai, moral, dan norma.

b. Pembinaan proses mengalami (experiencing) atau interaksi/transaksi dalam dunia afektif seseorang membuat terjadinya proses klarifikasi terhadap nilai moral norma, serta ajuan nilai moral norma (moral judgment) atau penalaran nilai moral norma (moral reasoning) kemudian pengendalian moral norma (moral control)." 
WAHANA

Volume 72, Nomor 2, Desember 2020

\subsection{Tujuan Pendidikan Nilai}

Tujuan dalam dunia pendidikan berarti sasaran yang ingin dicapai setelah mengajar suatu pokok atau subpokok bahasan yang sudah direncanakan. Tujuan pendidikan terhadap nilai yang fundamental yaitu untuk memaksimalkan mengembangkan kemampuan bersosialisasi/berinteraksi pada tahap tertinggi. Karena tujuan utama dari pendidikan nilai adalah memanusiakan manusia, membangun manusia secara paripurna dan membentuk insan kamil atau manusia seutuhnya yang memiliki kepribadian serta karakter yang baik dalam berinteraksi dengan manusia lainnya. Pendidikan nasional juga bertujuan memberikan arah untuk membentuk kepribadian yang mantap dan mandiri serta mempunyai rasa bertanggungjawab, kemasyarakatan dan kebangsaan (Yudianto, 2005:7). Menurut Suparno (2015:75), tujuan pendidikan nilai adalah menjadikan manusia berbudi pekerti. Begitu pula menurut Mulyana (2004: 119) menyatakan, bahwa pendidikan nilai bertujuan untuk membantu peserta didik mengalami dan menempatkan nilai-nilai secara integral dalam kehidupan mereka.

Nilai adalah sifat penting yang abstrak, nilai memiliki beberapa komponen/indikator oleh Rath dalam (Adisusilo, 2012:58) diuraikan dalam banyak nilai, adalah:

a. "Nilai memiliki arah atau tujuan (goal or purpose) untuk menggiring arah kehidupan yang dituju melalui proses pengembangan dan pengarahan.

b. Nilai memiliki aspirasi (aspirations) atau aspirasi terhadap seseorang untuk sesuatu yang berguna secara positif dan baik bagi kehidupan.

c. Nilai menggiring seseorang bertingkah laku (attitudes) atau seseorang bersikap sesuai dengan nilai acuan/moralitas yang ada di masyarakat.

d. Nilai merupakan hal menarik (interest) karena membuat seseorang terpikat untuk memikirkan, merenungkan, untuk diperjuangkan, dimiliki, dan dihayati.

e. Nilai mengaduk perasaan (feelings), seperti ketika hati nurani seseorang mengalami berbagai suasana hati yaitu bahagia, sedih, tertekan, bersemangat, dan sebagainya. f. Nilai juga terkait dengan kepercayaan atau keyakinan (beliefs and convictions) seseorang, karena nilainilai tertentu berkesinambungan dengan suatu kepercayaan atau keyakinan.

g. Nilai terdapat dalam aktivitas (activities) tingkah laku atau perbuatan yang sesuai dengan nilai tertentu. Maka, nilai tidak berhenti dalam pemikiran saja, namun menggerakkan atau membuat niatan agar melakukan suatu hal yang sesuai dengan maksud atau tujuan.

h. Nilai kadang muncul pada kesadaran pikiran atau hati nurani seseorang ketika mengalami situasi kebingungan atau menghadapi berbagai hal persoalan kehidupan (problem, worries, abstacles)."

Maka, dari kesimpulan indikator diatas didapatkan sebuah kejelasan integrasi nilainilai akhlak yang dapat diterapkan dalam sebuah pembelajaran baik secara formal atau informal.

\section{KESIMPULAN}

Kesimpulan Pendidikan nilai adalah penanaman dan pengembangan nilai-nilai pada setiap individu serta peserta didik untuk dapat menyadari dan memahami nilai-nilai kearifan yang mampu menempatkan secara sejajar dalam keseluruhan hidupnya.

Pendidikan pada dasarnya menumbuhkan nilai pada setiap pribadi manusia dalam kehidupannya sehari-hari. Nilai dari seseorang manusia tersebut akan menjadi tampak bersahaja jika dalam keadaan sadar dan memahami betul akan kesadaran tersebut. Mengejawantahkan nilai dalam kehidupan merupakan bagian dari tanggungjawab moralitas pendidikan untuk membentuk pribadi, akhlak, perilaku yang baik kepada sesama manusia. Model pendidikan nilai yang membentuk pribadi anak didik untuk menjadikan berakhlak diantaranya: model teknik pengungkapan nilai, model pengembangan kognitif moral, model analisis nilai, dan model tindakan sosial.

Kemudian strategi pendidikan nilai yang dapat diaplikasikan pada pendidikan dasar, menengah dan pendidikan tinggi, adalah: evocation, inculcation, moral reasoning, value 
WAHANA

Volume 72, Nomor 2, Desember 2020

clarification, value analysis, moral awareness, commitment approach, dan union approach.

\section{REFERENSI}

Adisusilo, Sutarjo. 2012. Pembelajaran Nilai Karakter. Jakarta: Rajawali Pers.

Djahiri. 1992. Menelusur Dunia Afektif, Pendidikan Nilai dan Moral. Bandung: Laboratorium Pengajaran PMP IKIP.

Khaeran. 1993. Pendidikan Nilai. Jakarta: Penerbit Gramedia.

Mulyana. 1999. Cakrawala Pendidikan Umum. Bandung: Ikatan Mahasiswa dan Alumni Pendidikan Umum, PPS IKIP Bandung.

Qiqi Yuliana Zakiyah. 2014. Pendidikan Nilai Kajian Teori dan Praktik di Sekolah. Bandung: Pustaka Setia.

Sita Acetylena. 2018. Pendidikan Karakter Ki Hadjar Dewantara. Malang: Intrans.

Subur, Subur, 'Pendidikan Nilai: Telaah tentang Model Pembelajaran', INSANIA : Jurnal Pemikiran Alternatif Kependidikan, $12.1 \quad$ (2007), 3-16 $<$ https://doi.org/10.24090/insania.v12i1.2 $15>$

Sumantri, Endang. 2006. Konsep Dasar Pendidikan Nilai. Bandung: Penerbit PT Pribumi Mekar.

Suparno, Paul. 2015. Pendidikan Karakter di Sekolah. Yogyakarta: Penerbit Kanisius.

Syaiful Bahri. 2013. Strategi Belajar Mengajar. Jakarta: Penerbit Rineka Cipta.

Undang-Undang Republik Indonesia Nomor 20 Tahun 2003 tentang Sistem Pendidikan Nasional. (Lembaran Negara Republik Indonesia Tahun 2003 Nomor 78, Tambahan Lembaran Negara Republik Indonesia Nomor 4301).
e-ISSN 2654-4954, p-ISSN 0853-4403

Yudianto, Suroso Adi. 2005. Manajemen Alam Sumber Pendidikan Nilai. Bandung: Mughni Sejahtera. 